\title{
INJURY FREQUENCY AND SEVERITY IN ROLLOVER CAR CRASHES AS RELATED TO OCCUPANT EJECTION, CONTACTS AND ROOF DAMAGE
}

\section{-AN ANALYSIS OF NATIONAL CRASH SEVERITY STUDY DATA-}

\author{
Donald F. HuelkE \\ Department of Anatomy and The University of Michigan Transportation Research Institute. Ann Arbor, \\ MI 48109, U.S.A. \\ and \\ Charles P. Compton \\ The University of Michigan Transportation Research Institute. The University of Michigan, Ann Arbor. \\ MI 48109. U.S.A.
}

(Received 5 April 1982; in revised form 6 January 1983)

\begin{abstract}
National Crash Severity Study data on tow-away. passenger cars that rolled over and had top damage due to ground contact were reviewed to study the occupants, overall injury severity, the infiuence of vehicle factors (occupant contacts and roof damage) on occupant injury frequency, and the effects of occupant ejection. The frequency of the more serious injuries or fatalities to rollover occupants who are not ejected is the same as in occupants in all types of crashes. The more serious injuries and fatalities are 17 times more frequent to ejected occupants in rollover crashes. Of the serious injuries more are sustained by occupant to ground contact than by occupant/roof interaction. Roof damage is not causally related to injury severity in rollover crashes.
\end{abstract}

During 1977-79 the National Highway Traffic Safety Administration (NHTSA) conducted a National Crash Severity Study (NCSS) providing a statistical sample of automobile crashes in the U.S. The resulting data provide a detailed statistical sample of accident and injury information on passenger cars and their occupants in tow-away crashes, permitting a number of studies not previously possible. The information available includes pertinent vehicle and environmental details as well as location, types and severity of injuries.

Crashes investigated in the NCSS program were sampled at various rates depending on the worst injury in a case vehicle: crashes involving fatalities or at least overnight hospitalization$100 \%$; the worst injured person transported to a medical facility-25\%, and all other eligible accidents-10\% (5\% at one NCSS area during part of the study) [Ricci, 1980].

To estimate the occurrances of the various injury levels, body regions involved, and some vehicle factors in this tow-away population, each case was assigned a weight equal to the inverse of its sampling fraction: one for a fatality or overnight hospitalization, four for treated and released, and ten or twenty for all others [Ricci, 1980].

In most of the tables of this report the weighted data are used; the missing data elements have been excluded. Thus, all tables may not contain the same total entries.

\section{Rollover crash frequency}

In the NCSS data analyzed for this report, there was an unweighted total of 12,050 accidents involving all types of crashes. Of these, $7 \%$ (836) were rollover crashes of all types, including 498 (4.1\%) passenger cars with primary top (roof) damage due to ground contact. Other types of rollover crashes may involve primary damage to other areas of the car than the top, or rollovers into poles, trees, etc. These were excluded from the rollover population used for analysis in this study. Rollovers in this report are defined as cars with primary roof damage due to ground contact. For comparative purposes the occurance of rollover car crashes from Michigan police accident data was 1.2\% (1979) and in Texas 2.3\% (1977). The Fatal Accident Reporting System (FARS-80) indicates that the principle point of impact was the top in $11.7 \%$ of fatal passenger car crashes. Of all these sources only the NCSS contains details on injury types by body location, and information on contacts, ejection, etc.; thus it is used for the subsequent analysis. 
Injury Rating

Injuries are rated by the 1976 edition of the Abbreviated Injury Scale (AIS). The Overall Injury Severity (OAIS) of an occupant, as indicated in the NCSS data. is ordinarily the AIS level of the most severe injury sustained by that occupant in the crash (Table 1) $\dagger$.

Injury Severity (OAIS) in various types of crashes

When passenger cars in "all types" of crashes (frontal, side, rear-end, rollover, etc.) are compared to only cars that rolled over, the distribution of injury severity (OAIS) is quite similar for each (Table 2). Occupants of these rollover cars have about the same frequency of the more severe injuries (OAIS 3-6) as those in "all types" of crashes, in both the ejected and non-ejected groups. However, there is a marked increase in OAIS 3-6 injury frequency associated with ejection. These more serious injuries and fatalities are 17 times more frequent to ejected occupants in rollover crashes (all crashes, 15x).

Car model type, rollover frequency and ejection

Car model type (standard, full size, compact, subcompact, etc.) data were reviewed to determine if various car types rolled over more frequently than others, or whether there were ejection frequency differences. The NCSS data indicates that of the rollover cars, the smaller cars are overrepresented when compared to their proportion in the NCSS tow-away accident population. The exceptions are subcompact U.S.A. cars (Pinto, Vega, Gremlin) and specialty

\begin{tabular}{ll} 
Table 1. The abbreviated injury scale (AIS) \\
\hline AIS & Injury Description \\
0 & None \\
1 & Minor \\
2 & Moderate \\
3 & Severe \\
4 & Serious \\
5 & Critical \\
6 & Maximum (currently untreatable) \\
\hline
\end{tabular}

Table 2. Injury severity frequencies, crash types and ejection

\begin{tabular}{rcccc}
\hline AIS & \multicolumn{2}{c}{ No Ejection } & \multicolumn{2}{c}{ Ejection } \\
& $\begin{array}{c}\text { Al1* } \\
\%\end{array}$ & $\begin{array}{c}\text { R/O+ } \\
\%\end{array}$ & Al1 & $\mathrm{R} / 0$ \\
& & & & $\%$ \\
0 & 70 & 61 & 3 & 2 \\
1 & 22 & 29 & 33 & 33 \\
2 & 5 & 7 & 20 & 14 \\
$3-6$ & 3 & 3 & 45 & 52 \\
\hline
\end{tabular}

\footnotetext{
* All Types of Crashes-frontal, side, rear, rollover, etc. (Occupants not ejected - 70,791; ejecred - 603

+ Rollovers only (Occupants not efected - 1,767; ejected (partial or complete) - 131
}

TThe 1976 AIS was used by all of the NCSS teams. The OAIS is an assessment of the total effect of multiple injuries on a crash victim measured in terms of severity. (The Abbreviated Injury Scale (AIS), 1976 Revision, American Association for Automotive Medicine, Morton Grove. IL). In the 1980 edition, the OAIS is referred to as MAIS (M = highest AIS level). 
pony cars (Camaro, Firebird, Mustang. Javelin, Barracuda) which did not rollover as often. Rollover involved cars have, on the average, an $8 \%$ ejection frequency. Although the smaller cars rolled over more often, the frequency of ejection from them. in general, is no greater than that noted for larger cars.

Objects contacted and injury sererity

The distribution of injury severity for each of the objects contacted in "all types" of crashes and in rollovers only, is shown in Fig. 1. In "all types" of crashes the steering assembly, the side interior surfaces, the roof/pillars, floor/controls or objects exterior to the car involve AIS 3-6 injuries more frequently than other items. In rollovers, when there is occupant contact with objects exterior to the car, two-thirds of these contacts cause AIS 3-6 injuries.

The distribution of contacts for each injury severity level is shown in Fig. 2. In "all types" of crashes the steering assembly accounts for $18 \%$ of the AIS 3-6 injuries folowed by the instrument panel (22\%) and side interior surfaces (21\%). However of the AIS 3-6 injuries, ejection (injuries due to objects exterior to the car) accounts for $41 \% ; 17 \%$ of the more severe injuries are due to contacts with frontal structures (instrument panel, steering assembly, A-pillar, mirror), and $18 \%$ to side structures. Characteristically in rollovers there is roof damage
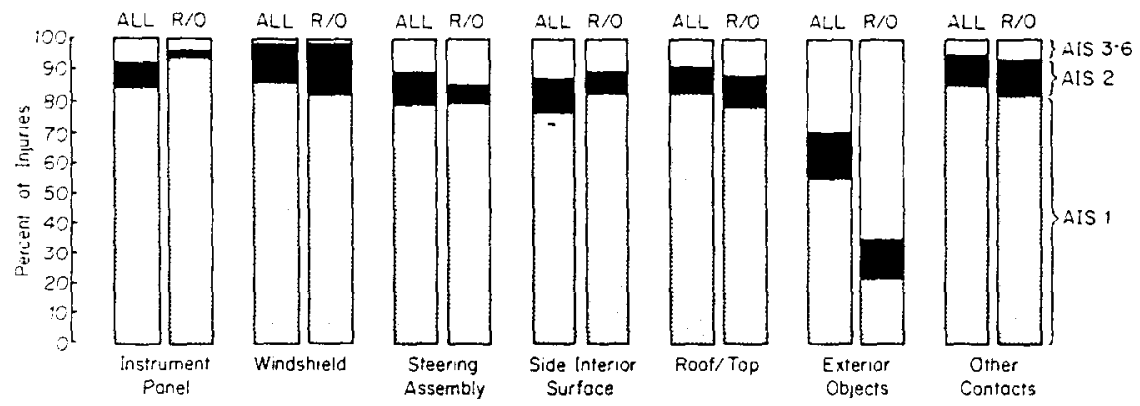

Fig. 1. Distribution of major contacts and injury severity in all types of crashes and in rollovers.

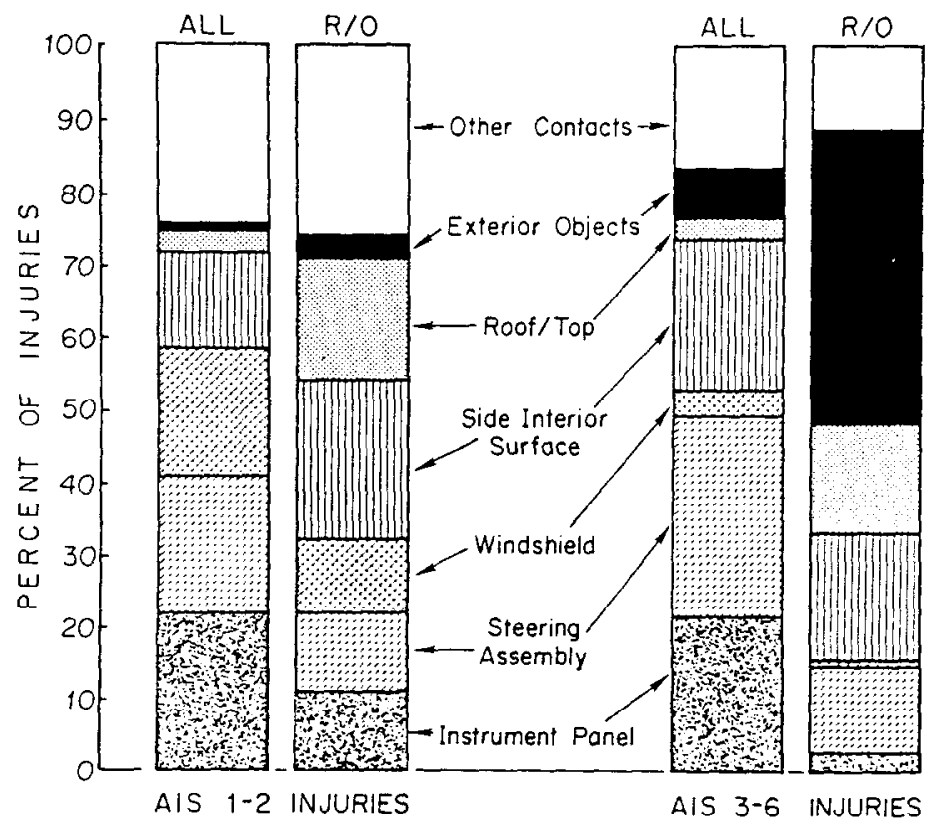

Fig. 2. Injury severity leveis and contacts. 
from roof/ground contact but. only $15 \%$ of these more serious rollover injuries are attributed to occupant contact to the roof or top (Fig. 2).

Thus frequency of contacts varies depending upon the type of crash. The exterior to the car contacts associated with severe injuries increase six fold when the car rolls over.

\section{Roof deformation classification}

Roof damage in the NCSS file is indicated by zones (Fig. 3) [SAE, 1980]. Note that zones $1-5$ extend from the top of the roof to the level of the hood (or beltline) or the car. Zone 1 is the top surface. Zone 2 is the area down to the roof side rail. Zones 3,4 , and 5 are three equal zones, between the roof side rail and the beltline, each equal in depth. Zones $6-8$ are equal zones of the door, between the beltline and the rocker panel. Zone 9 is below the rocker panel.

\section{Non-ejected occupant injury severity and roof deformation}

Of the 1767 weighted non-ejected occupants in the rollover cars, more than half $(61 \%)$ were in cars with roof damage in zone 3 , and $16 \%$ in zone 4 to the level of the middle third of the side glass (Table 3 ). Of the non-ejected occupants in rollover crashes only $4 \%$ of the occupants had injuries at the AIS 3-6 level (Table 3). These 70 seriously injured occupants were in cars with roof deformation of Zone 1 and $2(4 \%)$, Zone $3(44 \%)$, Zone $4(27 \%)$, Zone $5(14 \%)$ and Zones $6-7(19 \%)$.

Roof damage is an indicator of accident severity [Hight et al. 1972; Huelke et al., 1972: Huelke et al. 1973; Huelke et al. 1977; MacKay and Tappan, 1970]. The rate of the AIS 3-6 injuries increases as the roof deformation extends beyond Zone 3 .

Table 3. The extent of roof deformation and overall injury severity (non-ejected occupants)

\begin{tabular}{|c|c|c|c|c|c|c|c|c|}
\hline $\begin{array}{l}\text { Known } \\
\text { Roof } \\
\text { Crush } \\
\text { 2one } \\
\end{array}$ & $\begin{array}{l}0 \\
\underline{Z}\end{array}$ & $\underline{!}$ & $\begin{array}{l}2 \\
\stackrel{2}{2}\end{array}$ & $\begin{array}{l}3 \\
4 \\
2\end{array}$ & $\begin{array}{l}4+5 \\
\because \\
\end{array}$ & $\begin{array}{l}6 \\
2\end{array}$ & & \\
\hline $1+2$ & 70 & 27 & 1 & 2 & - & -- & 193 & 11 \\
\hline 3 & 64 & 26 & 7 & 2 & 1 & * & 1075 & 61 \\
\hline 4 & 50 & 37 & 6 & 5 & 1 & 1 & 279 & 15 \\
\hline 5 & 46 & 37 & 11 & 5 & 1 & $\cdots$ & 165 & 9 \\
\hline $6+7^{+}$ & 43 & 33 & 11 & 7 & 4 & 2 & 54 & 3 \\
\hline Total & 60 & 29 & 6 & 3 & 1 & * & 1767 & 100 \\
\hline
\end{tabular}

* Less than $0.5 \%$

+ No cars with Zones 8 \& 9 roof crush extent

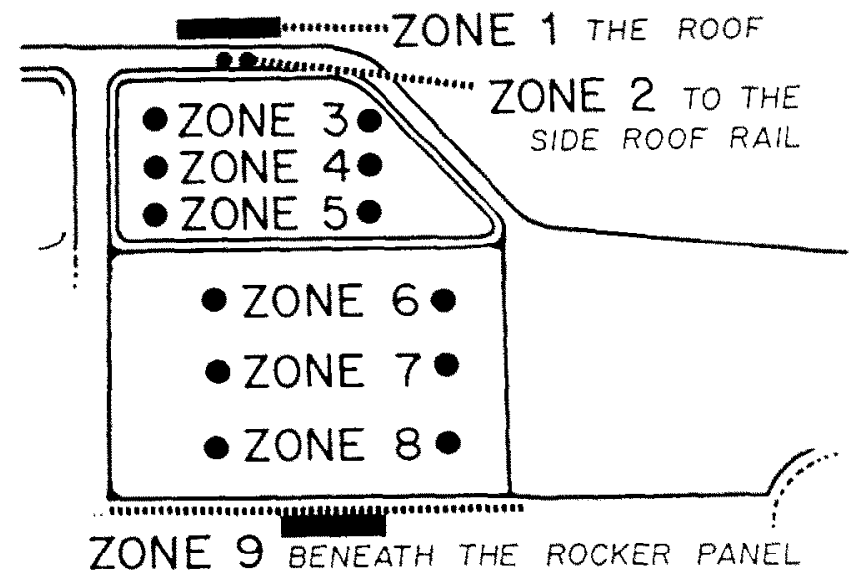

Fig. 3. Zones of roof deformation. 
Of the 1767 weighted non-ejected occupants, (Table 3) 701 , sustained 1588 injuries $\geq$ AIS 1 in cars with known extent of roof deformation. The distribution of non-ejected occupant injuries by body regions and zones of roof deformation is shown in Table 4.

In cars with little roof deflection (Zones 1 and 2). 99\% of the injuries are AIS 1 or 2; with greater roof deformation. (Zones 3-5) $94 \%$ of the injuries are AIS 1 or 2. But at the maximum roof crush of zones 6 and 7 , AIS 1 and 2 injuries are less frequent $(85 \%)$.

Body region injury secerity and ejection

In rollovers the head was the most often injured body region, but $93 \%$ of these injuries were AIS 1 or 2. Of those occupants with a more severe head injury (AIS 3-6), three-fourths were ejected (Table 5).

If the neck is injured in rollover crashes, $83 \%$ are of a less severe nature, agreeing with previous reports. [Juhl and Selrup. 1981, Langwieden et al. 1981] Most AIS 1-2 neck injuries are to non-ejectees.

Chest and abdominal injuries of AIS 1 or 2 are low in frequency, about $50 \%$, compared to $93 \%$ for the head and $83 \%$ for the neck. Most of these less severe torso injuries are to non-ejected occupants. Chest injuries of AIS 3-6 are equally divided between ejected and

Table 4 . The distribution of injuries by body regions and the extent of roof damage to non-ejected occupants in rollover crashes -Roof Crush Zone-

\begin{tabular}{|c|c|c|c|c|c|c|c|c|c|c|c|c|c|}
\hline \multirow{3}{*}{$\begin{array}{l}\text { Body } \\
\text { Regtons }\end{array}$} & \multicolumn{2}{|c|}{ Zone $1+2$} & \multicolumn{2}{|c|}{ Zone 3} & \multicolumn{2}{|c|}{ Zone 4} & \multicolumn{2}{|c|}{ Zone $S$} & \multicolumn{2}{|c|}{ Zone $6-7$} & \multicolumn{3}{|c|}{ All zanes } \\
\hline & \multicolumn{2}{|c|}{ AIs } & \multicolumn{2}{|c|}{ AIS } & \multicolumn{2}{|c|}{ AIS } & \multicolumn{2}{|c|}{ AYS } & \multicolumn{2}{|c|}{ AIS } & \multicolumn{3}{|c|}{ AIs } \\
\hline & $\leq 2$ & $\geq 3$ & $\leq 2$ & $\geq 3$ & $\leq 2$ & $\geq 3$ & $\leq 2$ & $\geq 3$ & $\leq 2$ & $\geq 3$ & & $\leq 2$ & $\geq 3$ \\
\hline & Ko. & No. & No. & No. & No. & No. & No. & No. & Nิo. & No. & $N$ & $(x) \pi$ & $7(7)$ \\
\hline Head & 35 & $!$ & 225 & 4 & 132 & 3 & 58 & 1 & 25 & 2 & 475 & $(96) ! 1$ & $(4)$ \\
\hline Neck & 18 & - & 64 & 4 & 27 & 8 & 12 & 2 & 2 & 1 & 123 & $(82) 15$ & $(18)$ \\
\hline Chene & $y$ & 1 & 22 & 15 & 8 & 6 & 18 & 4 & 3 & 5 & 58 & (53) 31 & $(47)$ \\
\hline Abdomen & 2 & $-\infty$ & $H$ & 5 & 6 & 2 & - & 1 & + & - & 19 & $(45) 8$ & $(54)$ \\
\hline Back & 13 & - & 60 & 4 & 21 & -- & 12 & $-\cdots$ & 1 & $\mathfrak{l}$ & 107 & (92) 5 & $(8)$ \\
\hline Lowet Ext. & 25 & $m$ & 146 & 3 & 55 & 2 & 45 & $\cdots$ & 13 & 1 & 284 & $(94) 6$ & $(6)$ \\
\hline \multirow[t]{2}{*}{ tppar Ext. } & 40 & $-\infty$ & 249 & 11 & 77 & 1 & si & 5 & 12 & $-\cdots$ & 429 & $(95) 1 \%$ & (5) \\
\hline & - & - & - & - & - & - & $\rightarrow$ & - & $\rightarrow$ & - & & & \\
\hline \multirow[t]{2}{*}{ Total } & 140 & 2 & 777 & 46 & 326 & 22 & 196 & 13 & 56 & 10 & 1495 & 93 & \\
\hline & 99 & 1 & 94 & 6 & 94 & 6 & 94 & 6 & 85 & 15 & & (94) & (6) \\
\hline
\end{tabular}

* Entudes Ais 1 s 2.

Table 5 . Injury severity and ejection in rollover crashes by body region

\begin{tabular}{|c|c|c|c|c|c|c|}
\hline & \multicolumn{3}{|c|}{ AIS $1+2$} & \multicolumn{3}{|c|}{ AIS $3-6$} \\
\hline & \multicolumn{3}{|c|}{ Ejected } & \multicolumn{3}{|c|}{ Ejected } \\
\hline & $\frac{\text { Yes }}{z}$ & $\frac{N o}{z}$ & (N) & $\frac{\text { Yes }}{7}$ & $\frac{\mathrm{No}}{\mathrm{z}}$ & $(\mathrm{N})$ \\
\hline Head & 15 & 85 & $(557)$ & 75 & 25 & (43) \\
\hline Neck & 9 & 91 & (135) & 44 & 56 & $(27)$ \\
\hline Chest & 12 & 88 & (68) & 55 & 45 & $(67)$ \\
\hline Abdomen & 35 & 65 & (26) & 70 & 30 & $(30)$ \\
\hline Back & 16 & 84 & $(128)$ & 33 & 67 & (9) \\
\hline Lower Extremity & 13 & 87 & $(327)$ & 78 & 22 & (27) \\
\hline Upper Extremity & 11 & 89 & $(487)$ & 32 & 68 & (25) \\
\hline
\end{tabular}


non-ejected occupants, but twice as many of the more severe abdominal injuries are found in ejected occupants.

Only $7 \%$ of back injuries are of the more severe type and the frequency of these injuries is twice as high in ejectees.

The more severe injuries of the lower extremity are. found about four times as often to ejectees; whereas upper extremity AIS 3-6 injuries are twice as frequent in those not-ejected from the car.

\section{Frequency of the more serious injuries and fatalities}

In rollover crashes, as in most other crash situations, AIS 3-6 injuries are infrequent (Table 6). The chest, extremities, and head are seriously injured more often than are the back, neck or abdomen. When the factor of ejection is eliminated, serious injuries of the chest and extremities predominate, with the other body areas seen less often (Table 6).

\section{Head and spinal column injuries, ejection and roof deformation}

Of the passenger cars that rolled over and had minor post-crash roof crush, no occupants were cjected and injuries to non-ejected occupants are infrequently noted with almust all of them AIS 1-2 (Tables 4 and 7 ).

There are few AIS 3-6 neck injuries at low and high roof levels of deformation: the majority occur in cars with roof deformation in Zones 3 and 4 (Tables 4 and 7). For the 15 occupants with AIS 3-6 neck injuries in rollover crashes who were not ejected, 12 sustained these injuries in cars with roof damage in Zones 3 and 4 , and 3 in Zones 5-7. Additionally, of the 123 AIS $\leq 2$ neck injuries in non-ejected occupants, 91 were sustained in cars with roof damage in Zones 3 and 4 .

Previous analysis of the NCSS data indicates that the data base represents a population of 62,062 occupants of passenger cars involved in tow-away accidents. [Huelke et al. 1981] Of all such persons, in all types of crashes, one in 300 had a cervical lesion in the range of AIS 3-6. For persons who were not ejected, this rate was one in 433 . For ejected occupants, the rate was one in 14.

If roof deformation were related to the more severe cervical injuries, one would expect more injuries in Zones 5-7, but this is not the case. Further substantiation of the lack of correlation between roof deformation and injury severity is shown in Table 7. Note that there are no occupants ejected from cars with minimal roof damage (Zones 1 and 2), suggesting a low speed rollover without sufficient force to cause ejection. About two thirds of all body injuries are related to Zone 3 roof damage but these data are on occupants who have been ejected from the car! Obviously then, roof crush and injuries cannot be directly correlated in these ejected occupants. Thus the data further substantiate previous findings that roof deformation is not directly or causally related to the more serious injuries of the head, neck or back, but may be indicative of a more severe type of crash. [Hight et al. 1972; Huelke et al. 1972: Huelke et al. 1973; Huelke et al. 1977; Mackay and Tappan, 1970]

Table 6 . AIS 3-6 injuries by body region in rollover crashes

\begin{tabular}{|c|c|c|c|c|}
\hline \multirow[b]{2}{*}{$\begin{array}{l}\text { Body } \\
\text { Region } \\
\end{array}$} & \multicolumn{2}{|c|}{$\begin{array}{l}\text { Al1 Rollover } \\
\text { Occupants }\end{array}$} & \multicolumn{2}{|c|}{$\begin{array}{c}\text { Non-Ejected } \\
\text { Rollover Occupants }\end{array}$} \\
\hline & $\mathrm{AIS}_{\mathrm{N}}^{3-6}$ & $\begin{array}{l}z \text { of Ald } \\
\text { Injurtes }\end{array}$ & AIs $\mathrm{N}^{3-6}$ & $\begin{array}{l}Z \text { of All } \\
\text { Injurtes }\end{array}$ \\
\hline Head & 43 & 2.2 & 11 & 0.6 \\
\hline Neck & 27 & 1.4 & 15 & 0.8 \\
\hline Chest & 67 & 3.4 & 30 & 1.6 \\
\hline Abdomen & 30 & 1.6 & 9 & 0.5 \\
\hline Back & 9 & 0.5 & 6 & 0.3 \\
\hline Extremfties & 52 & 2.7 & 23 & 1.2 \\
\hline
\end{tabular}


Table 7 . The distribution of injuries by body regions and the extent of roof damage to ejected occupants in rollover crashes

-Roof Crush Zone-

\begin{tabular}{|c|c|c|c|c|c|c|c|c|c|c|c|c|}
\hline \multirow[b]{2}{*}{$\begin{array}{l}\text { Body } \\
\text { Reglons }\end{array}$} & \multicolumn{2}{|c|}{$\begin{array}{c}\text { Zone } 1+2 \\
\text { AIs }\end{array}$} & \multirow{2}{*}{\multicolumn{2}{|c|}{$\begin{array}{r}\text { 2one } 3 \\
\text { AIs }\end{array}$}} & \multirow{2}{*}{\multicolumn{2}{|c|}{$\begin{array}{r}\text { Zone } 4 \\
\text { AIS }\end{array}$}} & \multicolumn{2}{|c|}{$\begin{array}{c}\text { Zone } 5 \\
\text { AIS }\end{array}$} & \multicolumn{2}{|c|}{$\begin{array}{c}\text { Zone } 6-7 \\
\text { AIS }\end{array}$} & \multicolumn{2}{|c|}{$\begin{array}{c}\text { All Zones } \\
\text { AIS }\end{array}$} \\
\hline & $\leq 2^{A I}$ & $\geq 3$ & & & & $\geq 3$ & $\leq 2$ & $\geq 3$ & $\leq 2^{A}$ & $\geq 3$ & $\leq 2$ & $\geq 3$ \\
\hline & No. & No. & No. & No. & No. & No. & No. & No. & No. & so. & No. & No. \\
\hline Head & -- & -- & 42 & 20 & 16 & 5 & 9 & 1 & 5 & 2 & 12 & 28 \\
\hline Neck & $-\infty$ & - & 22 & 31 & 9 & 22 & $\cdots$ & -- & 17 & -- & 48 & 53 \\
\hline Chest & -- & -- & $\because$ & 37 & 2 & 37 & -- & - & 7 & 7 & 20 & $8 !$ \\
\hline Abdamen & -- & $\cdots$ & 3 & 43 & 7 & 17 & 7 & -- & 17 & 10 & 30 & 70 \\
\hline Back & -- & -- & 71 & 13 & 17 & -- & -- & -- & -- & -- & 89 & 13 \\
\hline Lower Ext. & - & $=-$ & 51 & 22 & 5 & 6 & 10 & 3 & 2 & 2 & 68 & 33 \\
\hline Upper Exe. & -- & - & 63 & 10 & 6 & 3 & 10 & -- & 8 & -- & 87 & 13 \\
\hline Total No. & -- & -- & 263 & 176 & 62 & 90 & 36 & 4 & $\$ 2$ & 21 & 413 & 291 \\
\hline$(z)$ & & & 60 & 40 & 41 & 59 & 90 & 10 & 71 & 29 & 59 & 41 \\
\hline
\end{tabular}

*Includeg AIS 1 \& 2.

\section{SUMMARY}

Analysis of the NCSS data indicates a rollover frequency of $7 \%$ for passenger cars in tow-away crashes. The frequency of the more serious injuries or fatalities (AIS 3-6) to rollover occupants who are not ejected is the same for occupants involved in "all types" of crashes. But there is a significant increase (15-17 times) in these AIS 3-6 injuries when occupants are ejected.

In rollover crashes with roof damage due to ground contact, occupant ejection, and subsequent exterior object contact by the occupants, accounts for $41 \%$ of the AIS 3-6 injuries, with $17 \%$ of such injuries being sustained by contact to frontal structures and only $15 \%$ due to roof/top contacts.

In all types of cars involved in rollover crashes, $72 \%$ had roof damage that extended no further than into the level of the upper one-third of the side glass and included $49 \%$ of the occupants with AIS 3-6 injuries.

Most non-ejected occupants in rollover crashes had a low level injury severity. Of those with higher severity injuries, the chest and extremities predominate. AIS 3-6 injuries are relatively low in occurance to the neck, back and abdomen.

Roof deformation is not causally related to injury severity.

\section{REFERENCES}

Society of Automotive Engineers, Warrendale, PA. Collision Deformation Classification, SAE J224-Mar. 1980.

Hight P. V., Siegel A. W. and Nahum A. M.: Injury Mechanisms in Rollocer Collisions. Proc. 16th STAPP Car Crash Conf. Detroit, Michigan, 8-10 Nov., 1972.

Huelke D. F., Marsh IV, J. C. and Sherman H. W., Analysis of Rollover Accident Factors and Injury Causation. Proc. 16th Conference of the Am. Assn. for Auto. Med.. Chapel Hill, North Carolina. Oct. 19-21. 1972.

Huelke D. F.. Marsh IV. J. C., Dimento L. J., Sherman, H. W., and Ballard. Jr., W. J., Injury Causation in Rollover Accidents. Proc. 17 th Conference of the Am. Assn. for Auto. Med., Oklahoma City. Oklahoma, Nov. 14-17, 1973.

Hueike, D. F., Lawson. T. E. and Marsh IV. J. C., Injuries, restraints and vehicle factors in rollover car crashes. Accid. Anal. \& Prev., 9, 93-207, 1977.

Huelke, D. F., O’Day, J. and Mendelsohn, R. A.: Cervical injuries suffered in automobile crashes. $J$ of Neurosurg., 54. 316-322, 1981.

Juhl M. and Seerup K. K., Cervical Spine Injuries. Epidemiological Investigation. Medical and Social Consequences. Proc. VIth Intl. IRCOBI Conf., Salon de Provence (France), 8-10 Sept., 1981.

Langwieder K., Hummel T. and Saegerer F., Characteristics of Neck Injuries of Car Occupants. Proc. VIth Intl. IRCOBI Conf., Salon de Provence (France), Sept. 8-10, 1981.

MacKay G. M. and Tappan J. D., Field Studies of Rollover Performance. 1970 Intl. Auto. Safety Conf. Compendium, Rept. No. SAE 700417, Society of Automotive Engineers, New York, 1970.

Ricci L. L., NCSS Statistics: Passenger Cars. The Highway Safety Research Institute, UM-HSRI-80-36. June, 1980. 